\title{
Evaluating the Performance of Concentric Tube Heat Exchanger With And Without Dimples By Using Cfd Analysis
}

\author{
Dr. Syed Azam Pasha Quadri ${ }^{1}$, Shakib Javed .Shakil. Sheikh ${ }^{2}$ \\ ${ }^{I}$ (HOD Department of Mechanical Engineering, Lords Institute of Engineering and Technology Himayatsagar, \\ Hyderabad, Telangana, India) \\ ${ }_{2}^{2}(P G$ student, Mechanical Engineering, Lords Institute of Engineering and Technology Himayatsagar, \\ Hyderabad, Telangana, India)
}

\begin{abstract}
A heat exchanger is a device that is used to transfer thermal energy (enthalpy) between two or more fluids, between a solid surface and a fluid, or between solid particulates and a fluid, at distinctive temperatures and in thermal contact. Heat exchangers are vital engineering devices in many process industries since the efficiency and economy of the process largely depend on the performance of the heat exchangers. In present work, first concentric tube exchanger is designed and then dimple tube concentric heat exchanger is designed in solid works 2016 design software. CFD analysis is carried out in solid works flow simulation by using three different materials such as austenitic stainless steel, hastelloy and titanium. And efficient heat transfer rate for the given materials is studied in both types of heat exchangers.
\end{abstract}

Keywords: Heat Transfer, Thermal Analysis, CFD

\section{Introduction to heat exchanger}

The A heat exchanger is a device used to transfer heat between one or more fluids. The fluids may be separated by a solid wall to prevent mixing or they may be in direct contact. They are widely used in space heating, refrigeration, air conditioning, power stations, chemical plants, petrochemical plants, petroleum refineries, natural-gas processing, and sewage treatment. The classic example of a heat exchanger is found in an internal combustion engine in which a circulating fluid known as engine coolant flows through radiator coils and air flows past the coils, which cools the coolant and heats the incoming air.

Heat exchangers are one of the mostly used equipment in the process industries. Heat exchangers are used to transfer heat between two process streams. One can realize their usage that any process which involve cooling, heating, condensation, boiling or evaporation will require a heat exchanger for these purpose. Process fluids, usually are heated or cooled before the process or undergo a phase change. Different heat exchangers are named according to their application.

\subsection{Concentric Tube Heat Exchanger}

A typical concentric tube heat exchanger consists of one pipe placed concentrically in side another of larger diameter with appropriate fittings to direct the flow from one section to the another section. One fluid flows through the inner pipe and other fluid flows through the annular space. Concentric pipe heat exchangers can be arranged in various series and parallel arrangements to meet pressure drop and mean temperature difference requirements. The major use of double pipes exchangers for sensible heating or cooling of process fluids where small heat transfer area required. This configuration is also very suitable for one or both fluids are at high pressure because of the smaller diameter of the pipe. The major disadvantage is that concentric pipe heat exchangers are bulky and expensive per unit transfer surface. Inner tube being may be single tube or multitubes.

\section{Literature Survey}

Patel et al. A Review on Performance Evaluation and CFD Analysis of Double Pipe Heat Exchanger. Double pipe heat exchanger is one of simplest type of heat exchanger, generally used for the purpose of sensible heating or cooling. In this paper it describes the different techniques which may help to enhance the heat transfer rate. Heat exchangers are modified in space of annular, also using Nano particle in water and compared with the conventional heat exchanger. Double pipe heat exchanger is practically investigated and results are validated with Ansys CFD software. Results shows that heat transfer rate of modified heat exchanger are higher than the conventional heat exchanger.

Antony et al. Flow Analysis and Characteristics Comparison of Double Pipe Heat Exchanger Using Enhanced Tubes In this investigation, augmented surface has been achieved with dimples strategically located in a pattern along the tube of a concentric tube heat exchanger with the increased area on the tube side. Augmented surfaces 
to increasing the heat transfer coefficient with a consequent increase in the friction factor. In this analysis to modify the inner tube of double pipe heat exchanger using dimpled tube.

Kukulka et al. Development and evaluation of enhanced heat transfer tubes, Enhancement tube and smooth tubes are compared and material is enhanced $304 \mathrm{~L}$ stainless steel tube and steel. This experiment under performed by Turbulent flow in the range of Reynolds Numbers near 2900. Water as working fluid. Increases in heat transfer for most Enhancement tubes are in excess of $120 \%$ over smooth tubes and minimize the fouling rate. Inlet water flow was a constant rate of $6 \mathrm{~L} / \mathrm{min}$. After the prescribed time, the tubes were drained, samples dried and measurements made. Rate of fouling for the smooth stainless steel tubes were compared to the average values of the four dimpled tubes. Dimpled tubes minimize the fouling rate and also provide heat transfer performance gains in excess of $100 \%$.

Juin et al. Heat transfer enhancement in dimpled tubes, Coaxial-pipe heat exchanger using Six dimpled copper tubes of varying geometries were used for comparison with a standard smooth tube. This experiment under performed by turbulent flow. Water as test fluid and experimental method. Best dimpled tube was tube 6, which had the largest dimple depth-to-tube inside diameter ratio, dimple depth to-pitch ratio, dimple depth-to-dimple diameter ratio, and number of dimple columns. Tube 6 have high heat transfer coefficient are significantly larger (between 1.25 and 2.37times) than those for the smooth tube. Friction factor for all the dimpled tubes are 1.08 to 2.3 times higher than the value for the smooth tube.

Saleh et al. Flow and Heat Transfer Performance of a Dimpled-Inter Surface Heat Exchanger-an Experimental /Numerical Study. This paper presents and discusses the flow and heat transfer performance of a parallel/ counter flow heat exchanger, when the heat transfer surface is provided with dimples on one or both sides (cold fluid side and hot fluid side). Evaluation of the performance is based here on experimental and numerical data obtained for a typical such exchanger. It is found that the overall heat transfer rates that are 2.5 times greater for the dimpled surface compared to plain tube

Sai et al. Heat transfer in a conjugate heat exchanger with a wavy fin surface. A three dimensional computational study on conjugate heat exchangers was conducted Attention was specially directed towards studying extended surfaces used to increase heat transfer The strategy adopted in the present investigation of forced convection in a flow passage was to use the finite volume method Our implementation incorporated a simple based semi implicit solution algorithm which was applied to working equations formulated within the single phase catalo. The analysis allowed for marked changes in thermodynamic and flow properties. To better illuminate the flow and heat transfer characteristics in a flow passage bounded by two fins having wavy geometries we have plotted solutions in a three dimensions.

Kim et al. Numerical study on characteristics of flow and heat transfer in a cooling passage with protrusion-indimple surface, Four different protrusion heights were considered and protrusion height to channel height $(\mathrm{h} / \mathrm{H})$ of $0.05,0.10,0.15$, and 0.20 . This experiment under performed by turbulent flow. Water as test fluid. CFD analysis and Experimental method and $40 \%$ negligible pressure drop, $24 \%$ increase heat transfer, increase friction factor up to 5-6\% and volume goodness factor slightly increases by approximately $4 \%$.

\subsection{Design a Simple and Classic Design}

\section{Concentric Tube Heat Exchanger}

With its simple design and ability to operate under high pressures, the concentric tube heat exchanger is a valued resource in many industries for a range of purposes, from food preparation to material processing. In this type of heat exchanger, a pipe is placed inside another pipe, with cold fluid traveling through the inner tube and warm fluid traveling through the space between the inner tube and outer tube. These fluids can flow parallel to one another or they can run in counter flow. While flowing through the system, heat from the warm fluid is transferred through the inner tube to the cold fluid.

As different design schemes are developed, the designers and manufacturers behind the heat exchanger will turn to you the simulation engineer to run their simulations. This can, of course, be a rather time-consuming process, as the design can go through numerous minor modifications before the optimal configuration is achieved.

With the Application Builder, you can now take the physics and functionality behind your model and make it available in an easy-to-use simulation app. Once you have customized the app's layout to meet specific design needs, it can be shared with your colleagues and customers, who can then run their own simulations. Extending the scope of simulation capabilities not only establishes a more integrated workflow, but it also enables you to take on more simulation projects.

\subsection{Theory of Design and Analysis Design}

Consideration in designing heat exchangers, a number of factors that need to be considered are:

1. Resistance to heat transfer should be minimized.

2. Contingencies should be anticipated via safety margins, for example, allowance for fouling during operation. 
3. The equipment should be sturdy.

4. Cost and material requirements should be kept low.

\subsection{Materials Used For concentric tube Heat Exchangers}

A variety of materials are used in the design of concentric tube heat exchangers, including carbon steel, stainless steel, copper, bronze, brass, titanium and various alloys. Generally, the outer shell is made of a durable, high strength metal, such as carbon steel or stainless steel. Inner tubes require an effective combination of durability, corrosion resistance and thermal conductivity. Regular materials used in their construction are copper, stainless steel, and copper/nickel alloy. Other metals are used in device fittings, end bonnets and heads.

\section{Experimental Strategy}

Why concentric tube heat exchangers are preferred in this project?

Heat exchangers are used for transfer of heat between two fluids. Here we used tubular/concentric tube heat exchanger in this project. Generally concentric tube heat exchangers are used in food industries. As there are no gaskets are used in this type of heat exchanger it has low maintenance cost.

There are different types of heat exchangers in that we chose concentric tube heat exchanger because it has high usage in food industries etc.

The motive of heat exchanger is to transform the maximum heat. Materials play vital role in this part i.e. heat transfer depends upon the material properties i.e. on material which is applied to the tube. Thus materials having high thermal conductivity, corrosion resistant are used for the heat exchangers. Typically tube materials are copper alloy, stainless steel, carbon steel, non ferrous copper alloy, nickel, titanium. On basis of this we applied different materials for the tube. Next types of flows, parallel and counter flows. In general counter flow i.e. fluids flowing in opposite direction are more efficient.

In this project we are focusing on chemical and food processing industries we applied different materials for the tube and done analysis in two various flows i.e. parallel and counter flows. And studied which material is giving more efficient heat transfer in which flow. The material properties are studied. On basis of these studies those materials can be preferable for future scope.

\subsection{Flow Stimulation}

Solid Works Flow Simulation 2010 is a fluid flow analysis add-in package that is available for Solid Works in order to obtain solutions to the full Navier-Stokes equations that govern the motion of fluids. Other packages that can be added to Solid Works include Solid Works Motion and Solid Works Simulation. A fluid flow analysis using Flow Simulation involves a number of basic steps that are shown in the following flowchart.

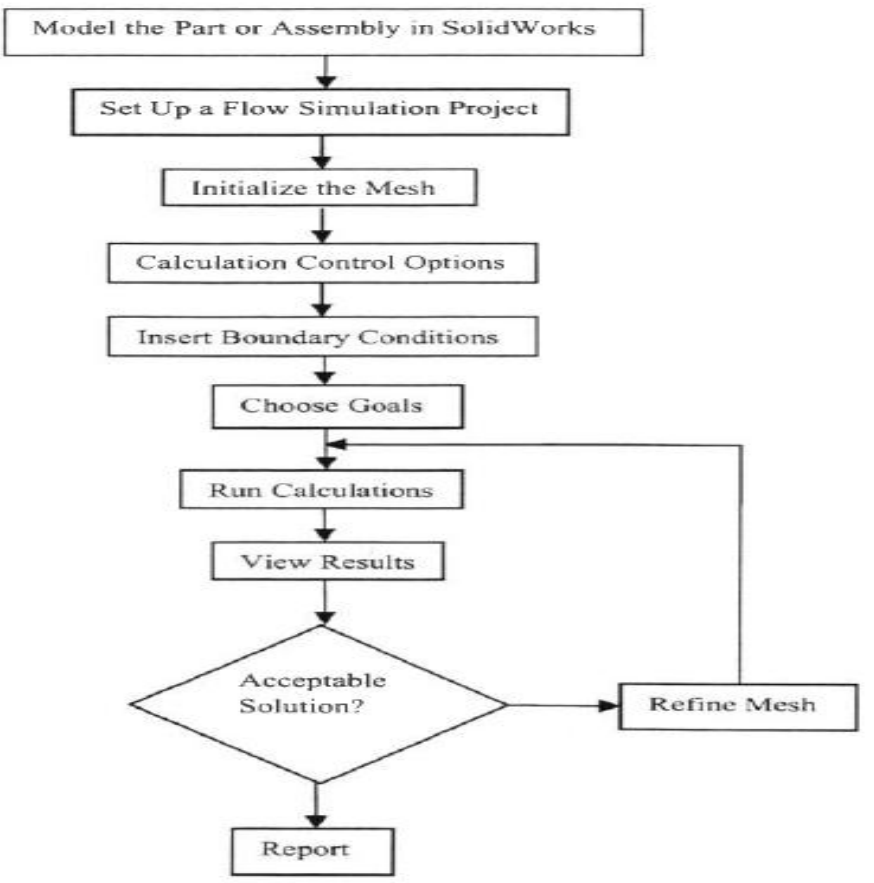

Fig.1. Flowchart for fluid flow analysis using Solid works Flow Simulation 
Evaluating The Performance Of Concentric Tube Heat Exchanger With And Without Dimples ....

\section{Designing of concentric tube heat exchanger}

Table.1.Geometrical Dimensions of Concentric tube heat exchanger with dimple and without dimple

\begin{tabular}{|c|c|c|c|}
\hline Sr.no & Dimensions & Without dimple & With dimple \\
\hline 1 & Diameter of Shell $(\mathrm{m})$ & 0.3 & 0.3 \\
\hline 2 & Inside diameter of tube $(\mathrm{m})$ & 0.2027 & 0.2027 \\
\hline 3 & Outside diameter of tube $(\mathrm{m})$ & 0.2191 & 0.2191 \\
\hline 4 & Length $(\mathrm{m})$ & 5 & 5 \\
\hline 5 & Dimple tube radius $(\mathrm{m})$ & - & 0.05 \\
\hline 6 & Distance between two dimples $(\mathrm{m})$ & - & 0.120 \\
\hline 7 & Circular pattern & - & 8 \\
\hline 8 & Linear pattern & - & 40 \\
\hline
\end{tabular}

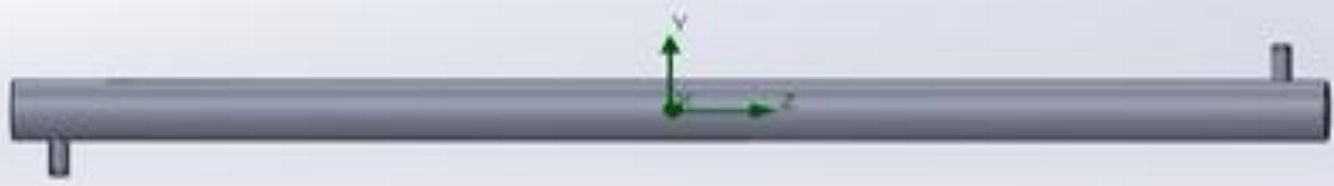

Fig.2. Concentric Tube Heat Exchanger Without Dimple

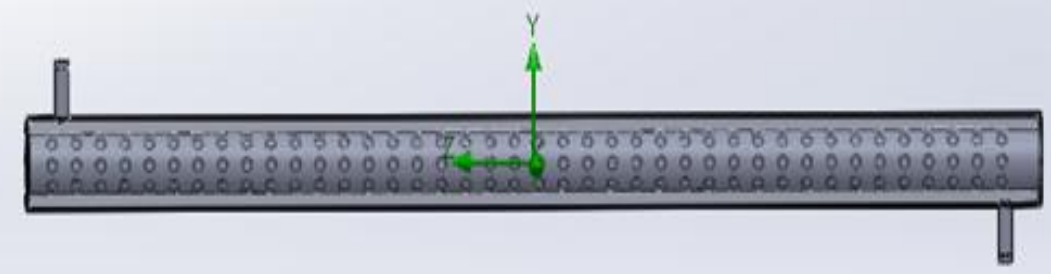

Fig.3. Concentric Tube Heat Exchanger With Dimple

\subsection{Material Properties}

Table.2. Different material used for tube design of concentric heat exchanger with dimples and without dimples

\begin{tabular}{|c|c|c|c|c|}
\hline Sr.no & Property & Austenitic stainless steel & Hastelloy & Titanium \\
\hline 1 & Density $\left(\mathrm{kg} / \mathrm{m}^{3}\right)$ & 7990 & 8890 & 4505 \\
\hline 2 & Specific heat $(\mathrm{J} / \mathrm{Kg} \mathrm{K})$ & 120 & 427 & - \\
\hline 3 & Thermal conductivity $(\mathrm{W} / \mathrm{mk})$ & 16.2 & 19 & - \\
\hline 4 & Electrical Conductivity & Dielectric & Dielectric & Conductor \\
\hline
\end{tabular}

\subsection{Insertion of Boundary Conditions}

Table.3. Boundary condition for concentric tube heat exchanger with dimples and without dimples

\begin{tabular}{|c|c|c|c|}
\hline Sr.no & Boundary conditions & Shell Side & Tube side \\
\hline 1 & Inlet temperature $\left({ }^{\circ} \mathrm{C}\right)$ & 39.85 & 90 \\
\hline 2 & Mass flow rate $(\mathrm{kg} / \mathrm{sec})$ & 0.120 & 0.220 \\
\hline 3 & Fluid type & Water & Viscous Fluid \\
\hline
\end{tabular}




\section{Result And Discussion}

6.1. For without dimple tube heat exchanger

Materials: Austenitic stainless steel 316L

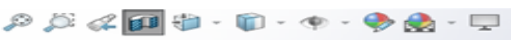
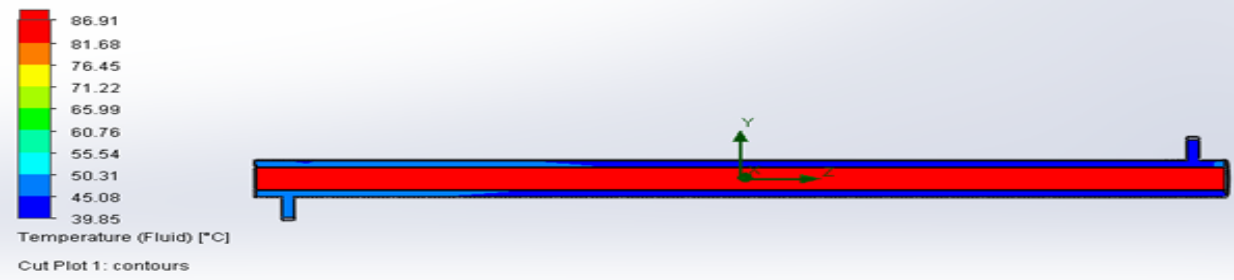

Fig .4. Solid work flow stimulation of temperature distrubution along tube for austenitic stainless steel

\section{Materials: Hasteolly}
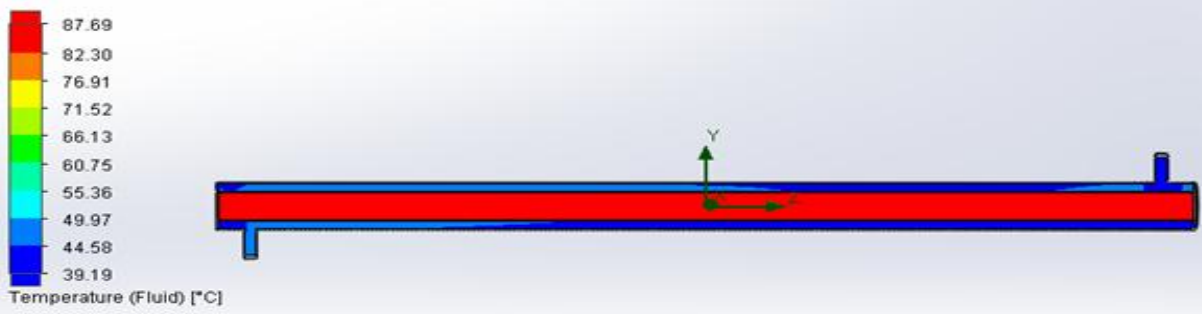

Cut Plot 1: contours

Fig .5. Solid work flow stimulation of temperature distrubution along tube for hasteolly

\section{Materials: Titanium}
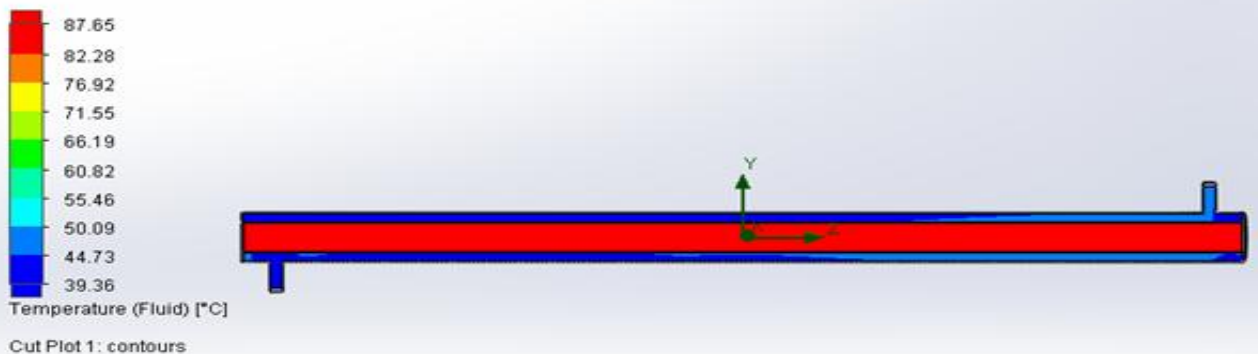

Fig .6. Solid work flow stimulation of temperature distrubution along tube for titanium

Table.4. Goal plot for without dimple tube heat exchanger

\begin{tabular}{|c|c|c|c|c|c|c|c|c|c|}
\hline Goal Name & \multicolumn{3}{|c|}{ Austenitic stainless steel } & \multicolumn{3}{|c|}{ Hasteolly } & \multicolumn{3}{|c|}{ Titanium } \\
\hline Min Fluid temperature(fluid 1$)^{\circ} \mathrm{C}$ & 26.04 & 39.37 & 39.85 & 22.90 & 29.75 & 39.83 & 23.01 & 29.80 & 39.01 \\
\hline Avg Fluid temperature(fluid 1$)^{\circ} \mathrm{C}$ & 57.52 & 61.69 & 61.14 & 57.66 & 59.81 & 60.99 & 57.66 & 59.81 & 60.99 \\
\hline Max Fluid temperature(fluid 1$)^{\circ} \mathrm{C}$ & 79.52 & 83.21 & 86.90 & 77.70 & 84.90 & 87.69 & 77.69 & 57.65 & 87.65 \\
\hline Heat Transfer Rate $(\mathrm{W})$ & 8.52 & 1.83 & 17.66 & 8.93 & 14.27 & 20.21 & 8.99 & 14.07 & 19.99 \\
\hline Min Fluid temperature $(\text { solid } 1)^{\circ} \mathrm{C}$ & 26.04 & 34.13 & 39.85 & 22.94 & 29.23 & 39.57 & 23.08 & 30.22 & 39.85 \\
\hline Avg Fluid temperature $(\text { solid } 1)^{\circ} \mathrm{C}$ & 50 & 52.16 & 53.23 & 48.11 & 51.83 & 54.01 & 48.11 & 51.46 & 54.04 \\
\hline Max Fluid temperature $(\text { solid } 1)^{\circ} \mathrm{C}$ & 55.93 & 58.60 & 59.51 & 57.82 & 61.49 & 63.78 & 57.85 & 61.40 & 63.92 \\
\hline
\end{tabular}




\subsection{For with dimple tube heat exchanger}

Materials: Austenitic stainless steel 316L
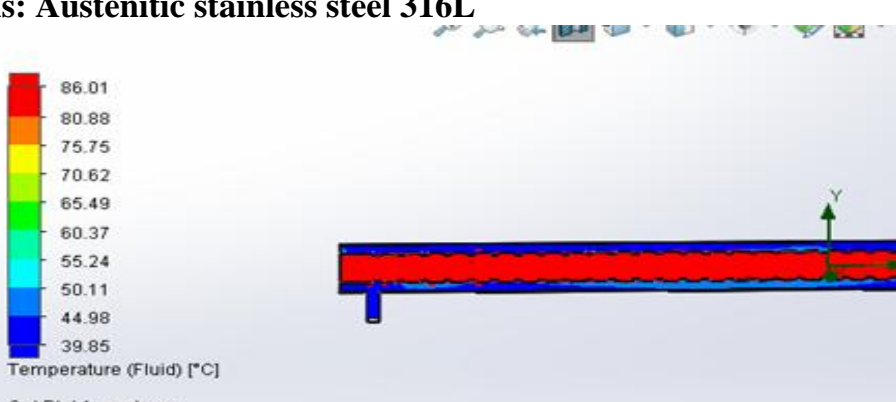

Cut Plot 1: contours

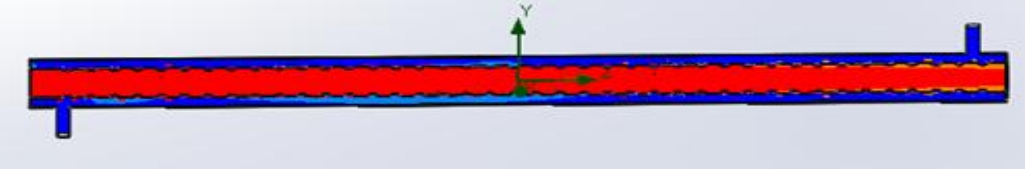

Fig.7. Solid work flow stimulation of temperature distrubution along dimple tube for austenitic stainless steel

\section{Materials: Hasteolly}
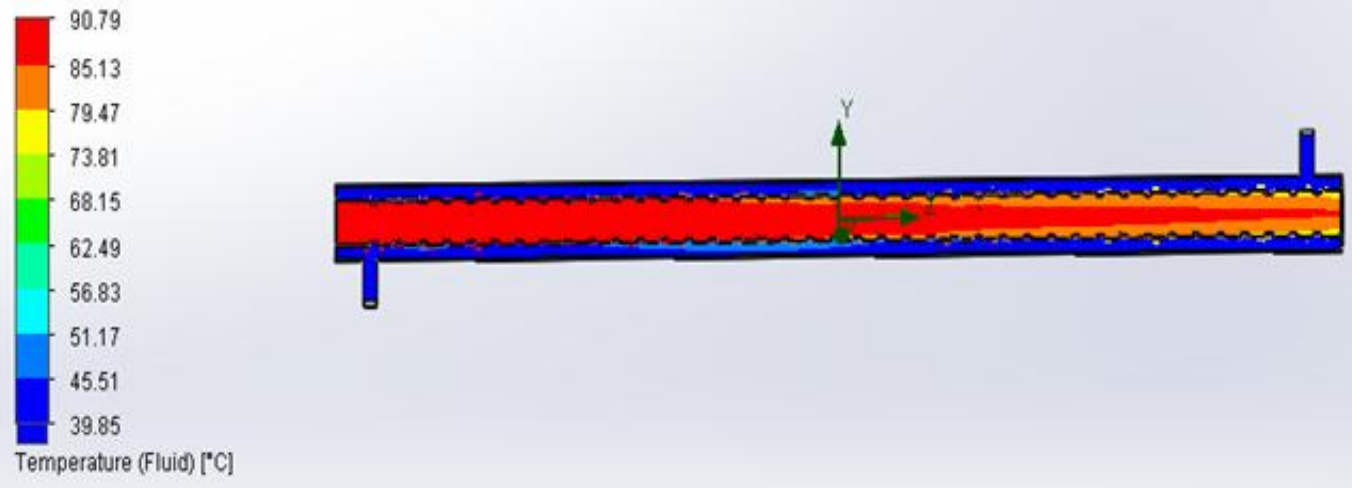

Cut Plot 1: contours

Fig.8. Solid work flow stimulation of temperature distrubution along dimple tube for hasteolly

\section{Materials:Titanium}

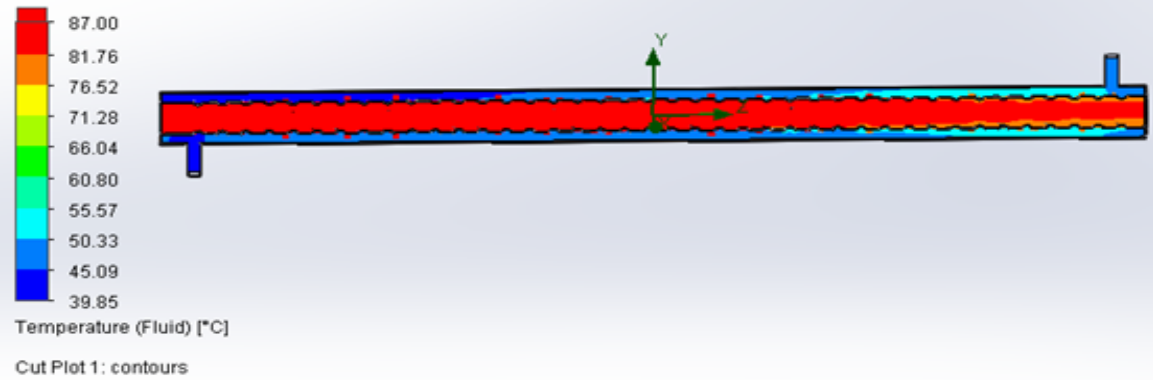

Fig.9. Solid work flow stimulation of temperature distrubution along dimple tube for titanium

Table.5. Goal plot for dimple tube concentric heat exchanger

\begin{tabular}{|c|c|c|c|c|c|c|c|c|c|}
\hline Goal Name & \multicolumn{3}{|c|}{ Austenitic stainless steel } & \multicolumn{3}{|c|}{ Hasteolly } & \multicolumn{3}{|c|}{ Titanium } \\
\hline Min Fluid temperature(fluid 1$)^{\circ} \mathrm{C}$ & 20.05 & 21.45 & 26.03 & 20.05 & 21.45 & 26.03 & 23.03 & 33.46 & 39.85 \\
\hline Avg Fluid temperature(fluid 1$)^{\circ} \mathrm{C}$ & 30.72 & 46.58 & 57.47 & 30.72 & 46.58 & 57.47 & 54.34 & 59.27 & 61.93 \\
\hline Max Fluid temperature(fluid 1$)^{\circ} \mathrm{C}$ & 66 & 76 & 86 & 77.69 & 90 & 90.78 & 79.63 & 85.34 & 87 \\
\hline Heat Transfer Rate $(\mathrm{W})$ & 28.26 & 39.11 & 46.22 & 28.11 & 38.11 & 49.83 & 20.10 & 29.92 & 39.99 \\
\hline Min Fluid temperature $(\text { solid } 1)^{\circ} \mathrm{C}$ & 20.05 & 21.49 & 26.16 & 20.05 & 21.49 & 26.16 & 23.06 & 33.51 & 39.85 \\
\hline Avg Fluid temperature $(\text { solid } 1)^{\circ} \mathrm{C}$ & 27.56 & 40.38 & 50.30 & 27.56 & 40.38 & 50.30 & 46.05 & 51.86 & 55.28 \\
\hline Max Fluid temperature $(\text { solid } 1)^{\circ} \mathrm{C}$ & 76.18 & 73.73 & 80.60 & 28.18 & 77.79 & 87.69 & 59.95 & 60.21 & 62.39 \\
\hline
\end{tabular}


Evaluating The Performance Of Concentric Tube Heat Exchanger With And Without Dimples ....

Table.6.Heat transfer rate of different material

\begin{tabular}{|c|c|c|}
\hline \multirow{2}{*}{ Materials } & \multicolumn{2}{|c|}{ Heat transfer rate (W) } \\
\cline { 2 - 3 } & With dimple & Without dimple \\
\hline Austenite Stainless steel 316L & 46.228 & 17.666 \\
\hline Hasteolly & 49.837 & 20.215 \\
\hline Titanium & 39.479 & 19.990 \\
\hline
\end{tabular}

\section{Conclusion}

1) Modeling and analysis of concentric heat exchangers is done

2) Modeling of heat exchanger without dimple tube and containing with dimple tubes is done in solid works using various commands.

3) CFD analysis is carried out in solid works flow simulation for both with and without dimple tube heat exchangers

4) The boundary conditions are given as inlet mass flow rate is $0.120 \mathrm{~kg} / \mathrm{sec}$ and hot water temperature is $90^{\circ}$ $\mathrm{C}$ and $0.220 \mathrm{~kg} / \mathrm{sec}$ for cold water temperature is $39.85^{\circ} \mathrm{C}$.

5) Thus the CFD analysis for both types of heat exchangers is carried out for these boundary conditions by applying three different materials, they are austenitic stainless steel, hastelloy and titanium

6) Material properties of these materials is study

7) Temperature distribution and heat transfer rate are noted.

8) From the results obtained by the analysis we can conclude that among the three materials applied hasteolly materials is showing efficient heat transfer rate for both in with dimple tube heat exchanger and without dimple tube heat exchanger.

9) Heat transfer rate for hasteolly dimple tube heat exchanger is $49.83 \mathrm{~W}$ and that for without dimple is 20.21 $\mathrm{W}$ in both the heat exchanger it's greater so we can suggest to used hasteolly material.

10) From the results we can also conclude that dimple tubes heat exchanger is more efficient than the heat exchanger without dimple tube.

\section{References}

[1]. Patel.H.S, Makadia.R.N , "A Review on Performance Evaluation and CFD Analysis of Double Pipe Heat Exchanger, Indian journal of research- ISSN - 2250-1991 Volume : 2- Issue : 4 - April 2013.

[2]. Antony luki.A, Ganesan.M, "Flow Analysis and Characteristics Comparison of Double Pipe Heat Exchanger Using Enhanced Tubes", IOSR Journal of Mechanical and Civil Engineering (IOSR-JMCE) e-ISSN: 2278-1684, p-ISSN: 2320-334X PP 16-21.

[3]. SK.M.Z.M, Saqheeb Ali, Mohan Krishna, Thermal Analysis of Double Pipe Heat Exchanger by Changing the Materials Using CFD.

[4]. David J. Kukulka, Rick Smith, Kevin G Fuller "Development and evaluation of enhanced heat transfer tubes", Applied Thermal Engineering 31 (2011) 2141-2145.

[5]. Juin Chen a, Hans Muller Steinhagen B, Georey G. Ducy a, "Heat transfer enhancement in dimpled tubes," Applied Thermal Engineering 21 (2001) 535-547.

[6]. Saleh.M.A, et.al.'Flow and Heat Transfer Performance of A Dimpled Inter Surface Heat Exchanger-an Experimental /Numerical Study". Applied Thermal Engineering 21 (2002).

[7]. Kim.J.E, Doo. J.H, Haa M.Y, Yoon.H.S, C. Son "Numerical study on characteristics of flow and heat transfer in a cooling passage with protrusion-in-dimple surface"' International Journal of Heat and Mass Transfer 55 (2012) 7257-7267.

[8]. Tsai, et.al."Heat transfer in a conjugate heat exchanger with a wavy fin surface"' International Journal of Heat and Mass Transfer 56 (1999).

[9]. http://web.iitd.ac.in/ pmvs/courses/mel709/classification-hx.pdf.

[10]. P.K Nag, heat and mass transfer, McGraw Hill education(India) Private limited, New Delhi. 